University of Wollongong

Research Online

Australian Institute for Innovative Materials -

Papers

Australian Institute for Innovative Materials

2013

Simple synthesis of yolk-shelled ZnCo204 microspheres towards enhancing the electrochemical performance of lithium-ion batteries in conjunction with a sodium carboxymethyl cellulose binder

\author{
Jingfa Li \\ Shandong University \\ Jiazhao Wang \\ University of Wollongong, jiazhao@uow.edu.au \\ David Wexler \\ University of Wollongong, davidw@uow.edu.au \\ Dongqi Shi \\ University of Wollongong, dongqi@uow.edu.au \\ Jianwen Liang \\ University of Science and Technology of China
}

See next page for additional authors

Follow this and additional works at: https://ro.uow.edu.au/aiimpapers

Part of the Engineering Commons, and the Physical Sciences and Mathematics Commons

Research Online is the open access institutional repository for the University of Wollongong. For further information contact the UOW Library: research-pubs@uow.edu.au 


\title{
Simple synthesis of yolk-shelled ZnCo204 microspheres towards enhancing the electrochemical performance of lithium-ion batteries in conjunction with a sodium carboxymethyl cellulose binder
}

\begin{abstract}
Mixed metal oxides have been attracting more and more attention recently because of their advantages and superiorities, which can improve the electrochemical performance of single metal oxides. These advantages include structural stability, good electronic conductivity, and reversible capacity. In this work, uniform yolk-shelled ZnCo2O4 microspheres were synthesized by pyrolysis of ZnCo-glycolate microsphere precursors which were prepared via a simple refluxing route without any precipitant or surfactant. The formation process of the yolk-shelled microsphere structure during the thermal decomposition of ZnCo-glycolate is discussed, which is mainly based on the heterogeneous contraction caused by non-equilibrium heat treatment. The performances of the as-prepared $\mathrm{ZnCo} 2 \mathrm{O} 4$ electrodes using sodium carboxylmethyl cellulose (CMC) and poly-vinylidene fluoride (PVDF) as binders are also compared. Constant current and rate charge-discharge testing results demonstrated that the ZnCo2O4 electrodes using CMC as the binder had better performance than those using PVDF as the binder. It was worth pointing out that the electrode using $\mathrm{CMC}$ as the binder nicely yields a discharge capacity of 331 $\mathrm{mA} \mathrm{h} \mathrm{g-1}$ after 500 cycles at a current density of $1000 \mathrm{~mA} \mathrm{g-1}$, which is close to the theoretical value of graphite (371 mA h g-1). Furthermore, the obtained synthetic insights on the complex hollow structures will be of benefit to the design of other anode materials for lithium ion batteries.
\end{abstract}

\section{Keywords}

microspheres, towards, enhancing, electrochemical, performance, lithium, ion, batteries, conjunction, sodium, znco2o4, carboxymethyl, simple, cellulose, binder, shelled, synthesis, yolk

Disciplines

Engineering | Physical Sciences and Mathematics

\section{Publication Details}

Li, J., Wang, J., Wexler, D., Shi, D., Liang, J., Liu, H., Xiong, S. \& Qian, Y. (2013). Simple synthesis of yolkshelled $\mathrm{ZnCo} 2 \mathrm{O} 4$ microspheres towards enhancing the electrochemical performance of lithium-ion batteries in conjunction with a sodium carboxymethyl cellulose binder. Journal of Materials Chemistry A: materials for energy and sustainability, 1 (48), 15292-15299

\section{Authors}

Jingfa Li, Jiazhao Wang, David Wexler, Dongqi Shi, Jianwen Liang, Hua-Kun Liu, Shenglin Xiong, and Yitai Qian 
Simple Synthesis of the Yolk-Shelled $\mathrm{ZnCo}_{2} \mathrm{O}_{4}$ Microspheres towards

\section{Enhancing the Electrochemical Performance by Using Sodium}

\section{Carboxymethyl Cellulose Binders for Lithium Ion Batteries}

Jingfa Li, ${ }^{\text {ab }}$ Jiazhao Wang, ${ }^{\text {a }}$ Xin Liang, ${ }^{a}$ Jianwen Liang ${ }^{c}$, Shulei Chou, ${ }^{\text {a }}$ Huakun Liu, ${ }^{\text {a Shenglin }}$ Xiong $^{\mathrm{b} *}$ and Yitai Qian ${ }^{\mathrm{bc}}$

${ }^{\mathrm{a}}$ Institute for Superconducting and Electronic Materials, University of Wollongong, Wollongong, NSW, 2522, Australia.

${ }^{\mathrm{b}}$ School of Chemistry and Chemical Engineering, Shandong University, Jinan, 250100, PR China.

${ }^{\mathrm{c}}$ Department of Chemistry, University of Science and Technology of China, Hefei, 230026, PR China

*Corresponding Authors: jiazhao@uow.edu.au (J. Z. Wang); chexsl@sdu.edu.cn (S. L. Xiong) 


\begin{abstract}
Mixed metal oxides have attracted more and more attention recently because of its advantage and superiority, which can meliorate and offset the electrochemical performance of the single metal oxide, including structural stability, electronic conductivity and reversible capacity. In this work, uniform yolk-shelled $\mathrm{ZnCo}_{2} \mathrm{O}_{4}$ microspheres were synthesized by pyrolysis of the ZnCo-glycolate microsphere precursors which were prepared via a simple refluxing route without any precipitant or surfactant. The formation process of the yolk-shelled microsphere structure during the thermal decomposition of $\mathrm{ZnCo-glycolate} \mathrm{is} \mathrm{discussed} \mathrm{and} \mathrm{mainly} \mathrm{based} \mathrm{on} \mathrm{the}$ heterogeneous contraction caused by non-equilibrium heat treatment. The performance of the as-prepared $\mathrm{ZnCo}_{2} \mathrm{O}_{4}$ electrodes using sodium carboxylmethyl cellulose (CMC), and poly(vinylidene fluoride) (PVDF) as binders were also compared. Constant current and rate charge-discharge testing results demonstrated that the $\mathrm{ZnCo}_{2} \mathrm{O}_{4}$ electrodes using $\mathrm{CMC}$ as the binder had the better performance than those using PVDF as the binder. It was worth pointing out that the electrode using CMC as the binder nicely yields a discharge capacity of $331 \mathrm{~mA} \mathrm{~h} \cdot \mathrm{g}^{-1}$ after 500 cycles at a current density of $1000 \mathrm{~mA} \cdot \mathrm{g}^{-1}$, which is close to the theoretical value of graphite $\left(371 \mathrm{~mA} \mathrm{~h} \cdot \mathrm{g}^{-1}\right)$. Furthermore, the obtained synthetic insights of the complex hollow structures will be of benefit in the design of other anode materials for lithium ion batteries.
\end{abstract}

Keywords: yolk-shell, metal oxides, microsphere, lithium battery 


\section{Introduction}

In recent years, mixed metal oxides, from combination of two transition metal oxides, or a transition metal oxide and a post-transition metal oxide, with the spinel structure of $\mathrm{AB}_{2} \mathrm{O}_{4}$, such as $\mathrm{MnCo}_{2} \mathrm{O}_{4}, \mathrm{NiCo}_{2} \mathrm{O}_{4}, \mathrm{CoMn}_{2} \mathrm{O}_{4}, \mathrm{ZnMn}_{2} \mathrm{O}_{4}, \mathrm{ZnCo}_{2} \mathrm{O}_{4}, \mathrm{ZnFe}_{2} \mathrm{O}_{4}$ et al [1-6], have been studied extensively and considered as ideal anode materials because of their complementarities and synergies for the two metal elements in the $\mathrm{Li}^{+}$charge-discharge process. For example, $\mathrm{NiCo}_{2} \mathrm{O}_{4}$ holds much better electronic conductivity, at least two orders of magnitude higher, and better electrochemical activity than either nickel oxide or cobalt oxide [7]. However, as we all know that large changes in volume appear during $\mathrm{Li}^{+}$insertion and extraction because of the conversion reaction mechanism, lead to the electrode pulverization of anode materials from current collectors, and thus resulting in poor cyclability. Therefore, solving this problem can greatly enhance the electrochemical behavior for lithium ion battery. On the one hand, hollow structures are considered as an effective way to overcome the problems due to the existence of nanoscaled interior cavities, which can buffer and accommodate the large volume change during $\mathrm{Li}^{+}$insertion and extraction [8]. In addition, the characteristic merits of the hollow structure, including large surface area, potential for high loading capacity and kinetically favorable open structure [9-12], are all beneficial for improving the electrochemical behaviors. Recently, $\mathrm{ZnCo}_{2} \mathrm{O}_{4}$ porous and hollow structures have been produced by solvothermal method, ultrasonic treatment, and spray pyrolysis to improve the electrochemical properties [13-15]. On the other hand, the choice of binder has been taken into account for improving the cycle life. Recently, there have been more extensive investigations of the sodium carboxymethyl cellulose (CMC) as a green binder replacing the traditional poly vinylidene fluoride (PVDF) in both anode materials, including graphite [16], silicon [17], $\mathrm{SnO}_{2}$ [18], $\mathrm{Fe}_{2} \mathrm{O}_{3}$ [19], and $\mathrm{Li}_{4} \mathrm{Ti}_{5} \mathrm{O}_{12}$ [20] et al, and cathode materials, including $\mathrm{LiCoO}_{2}$ [21], $\mathrm{LiFePO}_{4}$ [22], $\mathrm{LiNi}_{1 / 3} \mathrm{Mn}_{1 / 3} \mathrm{Co}_{1 / 3} \mathrm{O}_{2}$ [23] et al. CMC can be easily dissolved and processed in water by eliminating the usage of organic solvent during electrode preparation procedures. And more importantly, the electrochemical behavior improved greatly by using the CMC binder [16-23]. Due to both apparent advantages, reports on the application of CMC as the binder for lithium ion batteries have demonstrated its promising characteristics, such as its cycling stability, electro-chemical capacity improvement, and environmental friendliness [24, 25].

Herein, long cycling stability and excellent rate capability can be achieved via carefully controlling the hollow structured morphology and combined with CMC as the binder. By a refluxing method without adding any surfactant or precipitant, uniform ZnCo-glycolate microspheres were fabricated and served as the precursors to produce the yolk-shelled $\mathrm{ZnCo}_{2} \mathrm{O}_{4}$ microspheres. When adopting the CMC as the binder, the electrochemical performance for the yolk-shelled $\mathrm{ZnCo}_{2} \mathrm{O}_{4}$ microspheres, including cyclability, rate capability, are greatly enhanced compared with traditional PVDF binder. Therefore, combining the yolk-shelled $\mathrm{ZnCo}_{2} \mathrm{O}_{4}$ microspheres with using $\mathrm{CMC}$ as the binder provide more opportunities to improve the electrochemical behavior of these batteries for successful commercial applications. Furthermore, 
this general route can also be expanded to synthesize other complex oxides with respect to the facile preparation and the high yield of the product.

\section{Experimental Section}

All the chemical reagents, including $\mathrm{Zn}\left(\mathrm{CH}_{3} \mathrm{COO}\right)_{2} \bullet 2 \mathrm{H}_{2} \mathrm{O}(99 \%), \mathrm{Co}\left(\mathrm{CH}_{3} \mathrm{COO}\right)_{2} \bullet 4 \mathrm{H}_{2} \mathrm{O}(99 \%)$, and ethylene glycol $\left(\mathrm{HOCH}_{2} \mathrm{CH}_{2} \mathrm{OH}\right.$, A.R.), were supplied by Sigma-Aldrich Co. LLC. and used without any further purification.

Material Synthesis. The ZnCo-glycolate microsphere precursors were synthesized using a refluxing method. Typically, $1 \mathrm{mmol} \mathrm{Zn}\left(\mathrm{CH}_{3} \mathrm{COO}\right)_{2} \cdot 2 \mathrm{H}_{2} \mathrm{O}$ and $2 \mathrm{mmol} \mathrm{Co}\left(\mathrm{CH}_{3} \mathrm{COO}\right)_{2} \bullet 4 \mathrm{H}_{2} \mathrm{O}$ were dissolved in $50 \mathrm{~mL}$ ethylene glycol under stirring for about 30 minutes, then refluxed at $170{ }^{\circ} \mathrm{C}$ for $2 \mathrm{~h}$. The light purple precipitate was collected and washed by acetone and absolute ethanol for several times. To obtain $\mathrm{ZnCo}_{2} \mathrm{O}_{4}$ yolk-shell microspheres, we further calcined the $\mathrm{ZnCo}$-glycolate precursors at $350{ }^{\circ} \mathrm{C}$ for $5 \mathrm{~h}$ at a ramping rate of $0.4^{\circ} \mathrm{C} \cdot \mathrm{min}^{-1}$ under atmosphere.

Structural Characterization. The morphology and microstructure of the as-prepared particles were characterized by X-ray diffraction (XRD; GBC MMA 017), scanning electron microscopy (SEM; JEOL JSM 7500F, $5 \mathrm{kV}$ ) with JEOL energy-dispersive X-ray (EDX) spectroscopy and EDX mapping systems (30 kV), and transmission electron microscopy (TEM; JEOL 2011, 200 $\mathrm{KV}$ ). The thermal performances of the as-prepared $\mathrm{ZnCo-glycolate}$ were characterized by thermogravimetric analysis (TGA; TA Instruments 2000) under air at a flow rate of $30 \mathrm{~mL} \cdot \mathrm{min}^{-1}$ over a temperature range of $20-800^{\circ} \mathrm{C}$ with a ramp rate of $10^{\circ} \mathrm{C} \cdot \mathrm{min}^{-1}$.

Electrochemical Test. Electrochemical measurements were performed using coin cells (Size: CR2032) assembled in glove-box filled with argon. For preparing the working electrode, a mixture of $\mathrm{ZnCo}_{2} \mathrm{O}_{4}$, super-P (SP), and a binder, poly(vinylidene fluoride) (PVDF, Mw: 534,000, Sigma-Aldrich) or sodium carboxymethyl cellulose (CMC, average Mw: $\sim 250,000$, Sigma-Aldrich) at a weight ratio of $70: 20: 10$ in a solvent, consisting of either N-methyl-2-pyrrolidone (99.5\%, Sigma-Aldrich) or water, was pasted on a pure $\mathrm{Cu}$ foil. The electrolyte consisted of a solution of $1 \mathrm{M} \mathrm{LiPF}_{6}$ in ethylene carbonate (EC)/diethyl carbonate (DEC) (1:1, in wt \%). Galvanostatic tests of the assembled cells were carried out using an LAND 2010 system in the voltage range of $0.01-3.0 \mathrm{~V}$ ( $\mathrm{vs} \mathrm{Li}^{+} / \mathrm{Li}$ ). Cyclic voltammetry (CV) were performed using a a Biologic VMP-3 electrochemistry workstation.

\section{Results and discussion}

ZnCo-glycolate solid microspheres were fabricated by a green and facile route without any surfactant or precipitant then severed as the precursor for the fabrication of $\mathrm{ZnCo}_{2} \mathrm{O}_{4}$ yolk-shell microspheres. The formation reactions of the $\mathrm{ZnCo-glycolate} \mathrm{phases} \mathrm{can} \mathrm{be} \mathrm{described} \mathrm{in} \mathrm{the}$ following steps:

$$
\mathrm{CH}_{3} \mathrm{COO}^{-}+\mathrm{H}_{2} \mathrm{O} \leftrightarrow \mathrm{CH}_{3} \mathrm{COOH}+\mathrm{OH}^{-}
$$




$$
\begin{aligned}
& \mathrm{HOCH}_{2} \mathrm{CH}_{2} \mathrm{OH}+2 \mathrm{OH}^{-} \leftrightarrow{ }^{-} \mathrm{OCH}_{2} \mathrm{CH}_{2} \mathrm{O}^{-}+2 \mathrm{H}_{2} \mathrm{O} \\
& 3^{-} \mathrm{OCH}_{2} \mathrm{CH}_{2} \mathrm{O}^{-}+\mathrm{Zn}^{2+}+2 \mathrm{Co}^{2+} \rightarrow \mathrm{ZnCo}_{2}\left(\mathrm{OCH}_{2} \mathrm{CH}_{2} \mathrm{O}\right)_{3} \downarrow
\end{aligned}
$$

It should be mentioned that the $\mathrm{H}_{2} \mathrm{O}$ is from the acetate under high temperature. Figure 1 presents the SEM and TEM images of the precursor. The precursor is composed of dispersed microspheres with a diameter of about $0.8 \sim 1.2 \mu \mathrm{m}$ as indicated in Figure 1(a). The high-magnification SEM image (Figure 1(b)) shows that the surface of the microspheres is quite rough but stable. TEM image in Figure 1(c) further confirms that the microspheres are relatively uniform and solid.
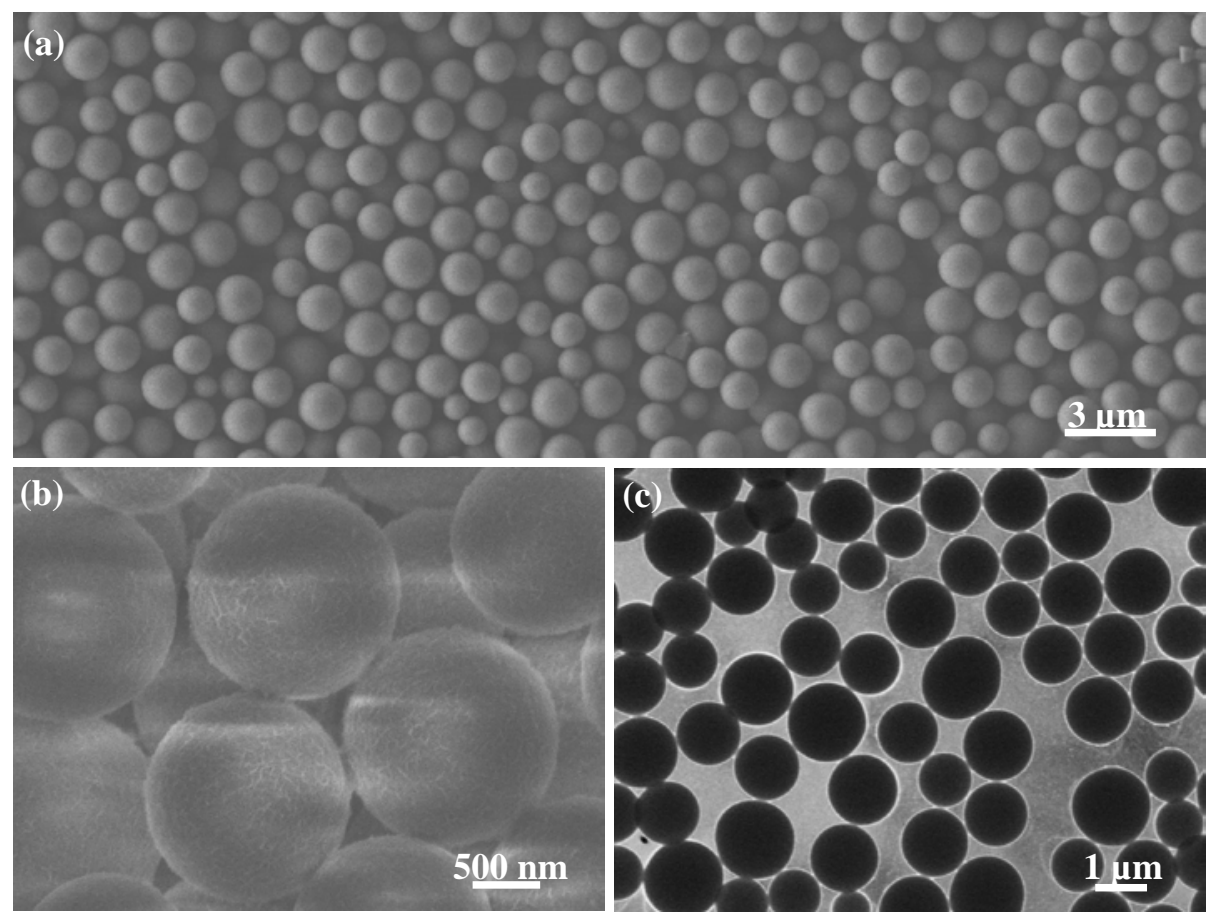

Figure 1. SEM (a, b) and TEM images (c) of the as-synthesized ZnCo-glycolate precursor fabricated by refluxing at $170{ }^{\circ} \mathrm{C}$ for $2 \mathrm{~h}$.

Figure 2(a) shows the TGA and DrTGA results of the thermal behavior of solid ZnCo-glycolate microspheres in air. There are two weight loss, the first weight loss below $200{ }^{\circ} \mathrm{C}$ is attributed to the loss of physically and chemically adsorbed ethylene glycol or other organic molecules, while the second prominent one is due to the thermal decomposition of these solid precursors into $\mathrm{ZnCo}_{2} \mathrm{O}_{4}$ in the presence of an air stream used in the TGA measurement. The large total weight loss of around $40.4 \%$ originated from the organic species such as $\mathrm{CH}_{3} \mathrm{COO}^{-}$and polymerized EG is considered as an important factor to obtain the yolk-shelled morphology because two contrary forces exist induced by oxidative degradation of the organic molecules. The DrTGA curve shows a sharp exothermic peak at $310.8{ }^{\circ} \mathrm{C}$, corresponding to the dominant mass loss. To ensure the complete decomposition of the precursor, we chose $350{ }^{\circ} \mathrm{C}$ as the calcinations temperature for the synthesis of $\mathrm{ZnCo}_{2} \mathrm{O}_{4}$. Figure 2(b) shows the XRD patterns of the sample before and after calcining at $350{ }^{\circ} \mathrm{C}$ for $5 \mathrm{~h}$. A broad and weak peak at around $11^{\circ}$ for the top patterns is the 
characteristic of metal glycolates [26]. For the down patterns, all of the reflections could be indexed as face-centered-cubic (fcc) $\mathrm{ZnCo}_{2} \mathrm{O}_{4}\left(\mathrm{a}_{0}=8.034 \AA\right.$; space group Fd3m (227), JCPDS no. 23-1390) with a spinel structure by comparing with the standard patterns as illustrated using green line in Figure 2(b).
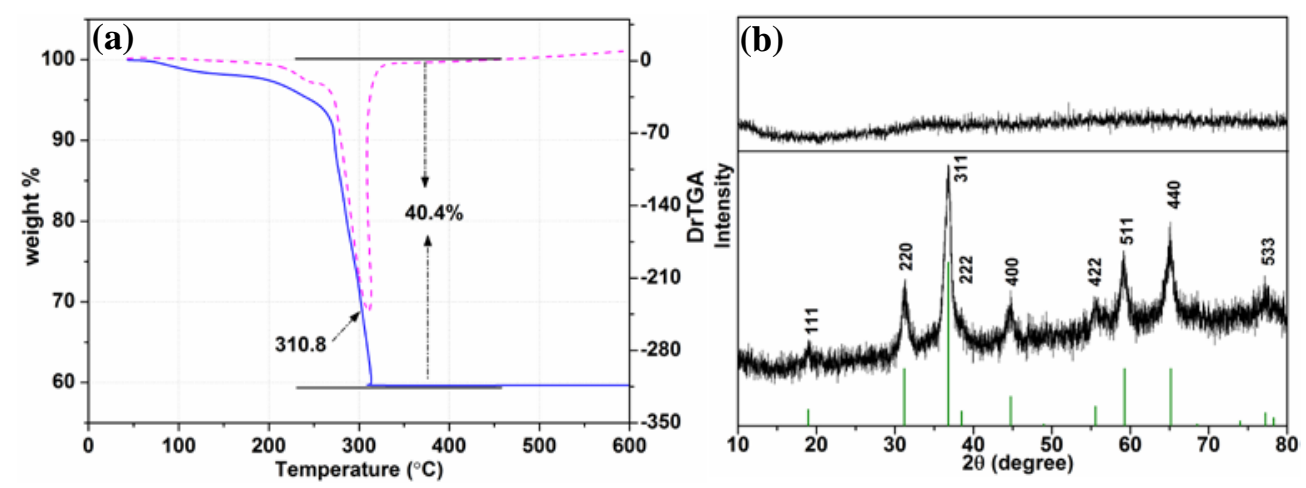

Figure 2. (a) TGA and DrTGA curves for the precursors in a flowing air. (b) XRD patterns of the $\mathrm{ZnCo-glycolate} \mathrm{precursor} \mathrm{(top)} \mathrm{and} \mathrm{the} \mathrm{resulting} \mathrm{porous} \mathrm{ZnCo}_{2} \mathrm{O}_{4}$ samples (down) after calcining at $350{ }^{\circ} \mathrm{C}$ for $5 \mathrm{~h}$.

SEM and EDX mapping images with the corresponding data of the as-obtained $\mathrm{ZnCo}_{2} \mathrm{O}_{4}$ particles are shown in Figure 3. A panoramic and low magnification SEM images in Figure 3(a) shows that the final sample after calcining reserved the overall spherical morphologies. Interestingly, it is observed that a significant fraction of the microspheres have cracks on their surface. A typical broken yolk-shelled microsphere is shown in Figure 3(b); a shell together with a yolk with the diameter of $600 \mathrm{~nm}$ can be clearly observed, the wall thickness of which is determined to be about $50 \mathrm{~nm}$. Practically, the core is highly porous and composed of nanosized subunits. Figure 3(c) contains the EDX mapping images for Zn, Co, and O, showing the good distribution of elements in the composite. It is worth noting that in a high accelerating voltage (30 $\mathrm{kV}$ ) the yolk shell structure are transparent and clear even for unbroken microspheres. The EDX spectrum in Figure 3(d) shows that only the elements Zn, Co, and O are present in the sample except $\mathrm{Al}$ from the substrate, indicating its high purity. And the mole ratio of $\mathrm{Zn} / \mathrm{Co}$ is 0.48 , very close to the theoretical value of 0.5 . 

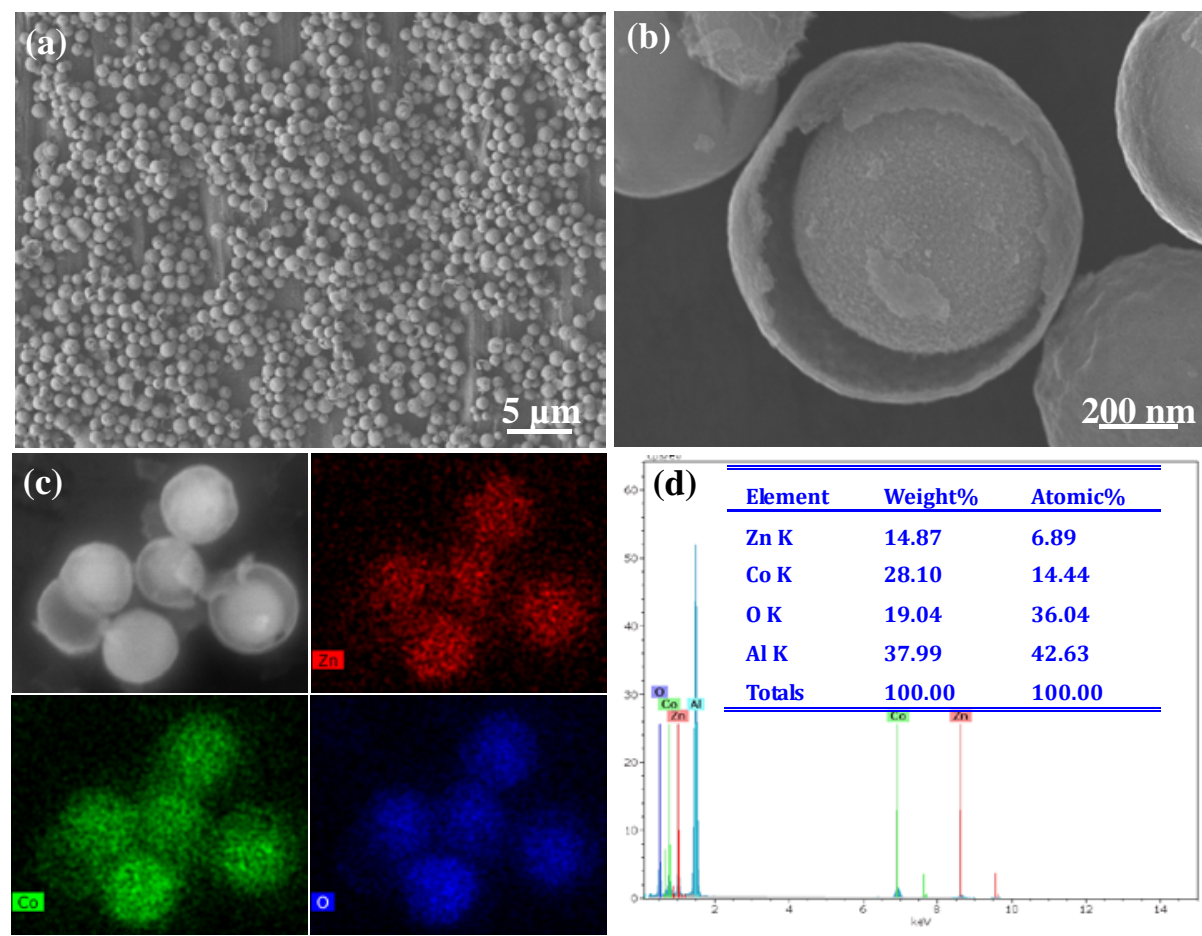

Figure 3. (a, b) Low and high magnification SEM images of the $\mathrm{ZnCo}_{2} \mathrm{O}_{4}$ products annealing at $350{ }^{\circ} \mathrm{C}$ for $5 \mathrm{~h}$. (c, d) Elemental mappings of $\mathrm{ZnCo}_{2} \mathrm{O}_{4}$ yolk-shell microspheres and EDX spectrum with the table data.

TEM images further confirm the yolk-shelled structure of the as-synthesized microspheres. As can be seen from the Figure 4(a) and Figure 4(b), clear gaps between the outer shell and inner yolk can be observed obviously. TEM image of a single microsphere in Figure 4 (b) confirms that the wall thickness of the shell is about $50 \mathrm{~nm}$ with a yolk of $600 \mathrm{~nm}$. A representative high-resolution TEM (HRTEM) image selected from the marked area in Figure 4 (b) is shown in Figure 4 (c). The observed and calculated $d$-spacings from the HRTEM image were $0.47 \mathrm{~nm}$ and $0.27 \mathrm{~nm}$, which match well with the $d$-spacing of $\{111\}$ and $\{311\}$ facets of cubic $\mathrm{ZnCo}_{2} \mathrm{O}_{4}$, correspondingly. The selected area electron diffraction (SAED) patterns in Figure 4 (d) indicate the nature of polycrystalline and all the diffraction rings can be indexed as (111), (220), (311), (400), (511), and (440) from the inside out, respectively. 

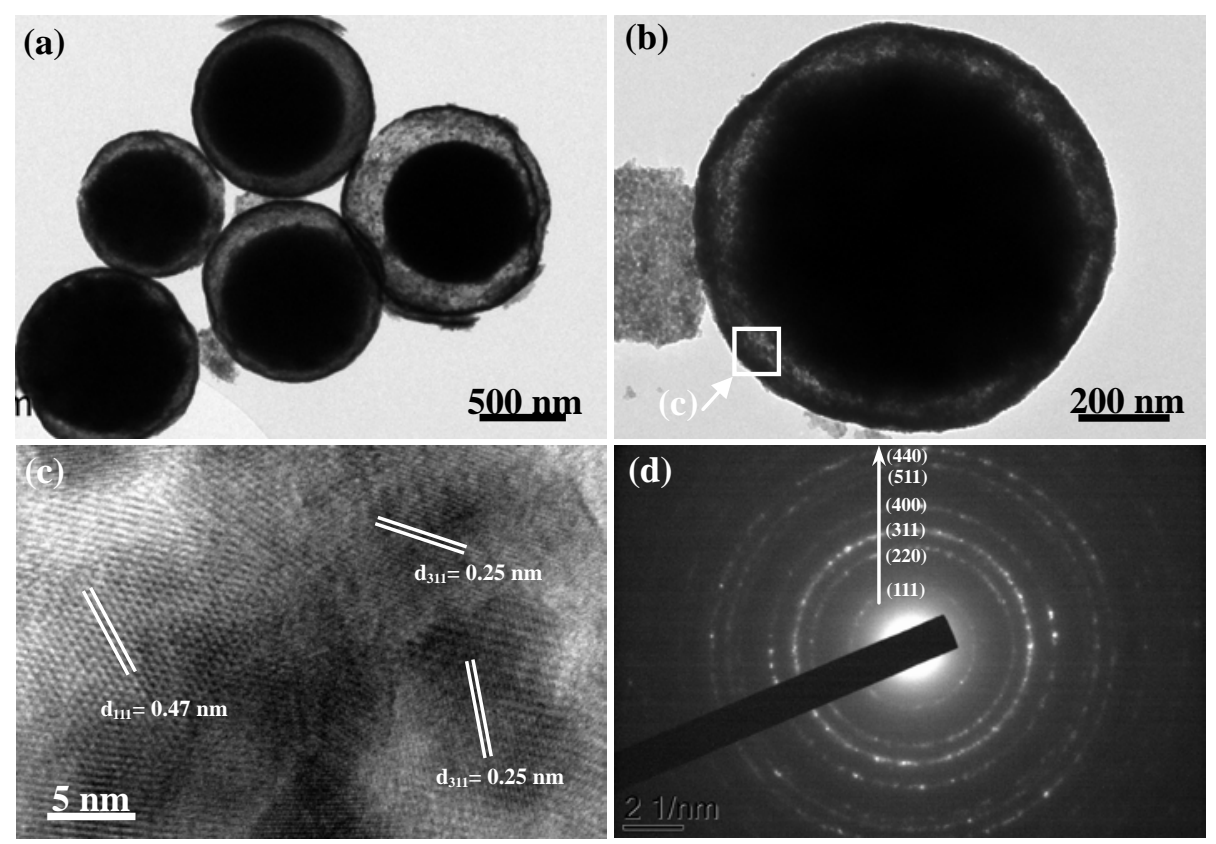

Figure 4. (a, b) Low and high resolution TEM images of the yolk-shelled $\mathrm{ZnCo}_{2} \mathrm{O}_{4}$ microspheres. (c) A high-resolution TEM image at the edge of the microsphere and (d) the corresponding SAED patterns.

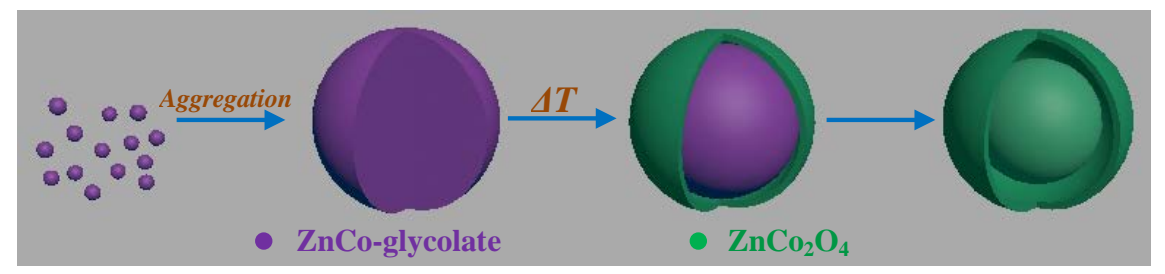

Figure 5. Schematic illustration of the formation of $\mathrm{ZnCo}_{2} \mathrm{O}_{4}$ yolk-shelled microspheres.

Figure 5 clearly shows the schematic illustration of the formation process of $\mathrm{ZnCo}_{2} \mathrm{O}_{4}$ yolk-shelled microspheres. In the initial synthesis procedure, $\mathrm{ZnCo-glycolate} \mathrm{nuclei} \mathrm{are} \mathrm{formed}$ due to the strong interlinked ability of ethylene glycol under the refluxing at $170{ }^{\circ} \mathrm{C}$, which possessed high surface energies and tended to aggregate to spherical structure to reduce the free energy. Afterwards, relative uniform microspheres are obtained due to the famous "Oswald ripening" process, driven by minimization of the surface energy. The fabrication of the yolk-shelled structure is mainly based on the heterogeneous contraction caused by the non-equilibrium heat treatment process during the thermal decomposition of $\mathrm{ZnCo-glycolate} \mathrm{[27]}$ Firstly, with heating in air at a ramp rate of $0.4{ }^{\circ} \mathrm{C} \cdot \mathrm{min}^{-1}, \mathrm{ZnCo}_{2} \mathrm{O}_{4}$ shell is formed on the surface of the microspheres as a result of the occurrence of a temperature gradient $(\Delta T)$ along the radial direction. Then, when arriving at $350{ }^{\circ} \mathrm{C}$, the inner ZnCo-glycolate core starts to decompose into $\mathrm{ZnCo}_{2} \mathrm{O}_{4}$ by the continuing calcination, and finally a $\mathrm{ZnCo}_{2} \mathrm{O}_{4}$ yolk-shelled microsphere is obtained. 

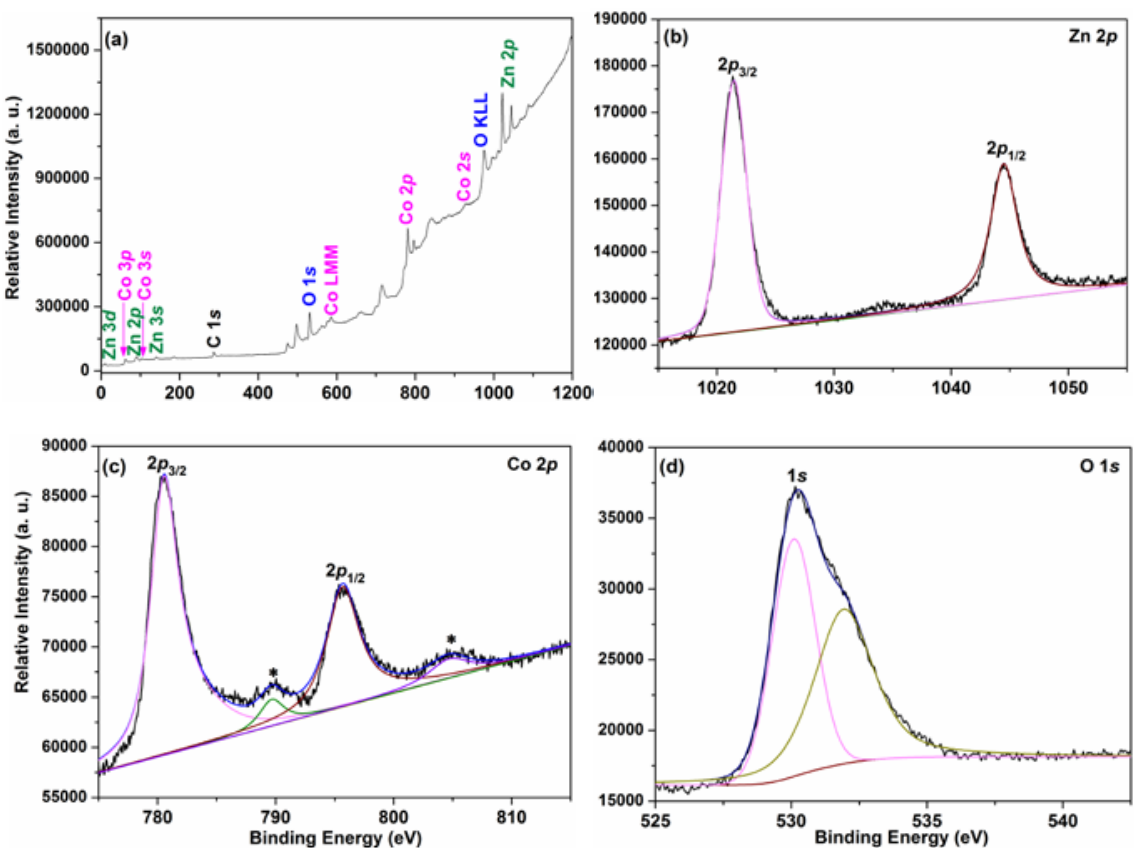

Figure 6. XPS spectra of (a) survey spectrum, (b) $\mathrm{Zn} \mathrm{2p}$, (c) Co 2p, and (d) $\mathrm{O}$ 1s for $\mathrm{ZnCo}_{2} \mathrm{O}_{4}$ yolk-shelled microspheres.

The X-ray photoelectron spectra (XPS) shown in Figure 6 were collected to investigate the surface electronic state and the composition of the $\mathrm{ZnCo}_{2} \mathrm{O}_{4}$ yolk-shelled microspheres. The binding energies obtained in the XPS analysis were corrected for specimen charging by referencing the C 1s line to $284.60 \mathrm{eV}$. Figure 6(a) shows a typical survey XPS spectrum and indicates the presence of $\mathrm{Zn}$, Co and $\mathrm{O}$ as well as $\mathrm{C}$ from the reference and the absence of other impurities. Figure 6(b) shows the two major peaks centered at 1044.4 and $1021.3 \mathrm{eV}$, which is the characteristic of $\mathrm{Zn}^{2+}$ with the orbits of $\mathrm{Zn} 2 \mathrm{p}_{3 / 2}$ and $\mathrm{Zn} 2 \mathrm{p}_{1 / 2}$, respectively [28]. The Co $2 \mathrm{p}$ XPS spectrum in Figure 6(c) consists of two main lines $\left(2 \mathrm{p}_{3 / 2}\right.$ at $\sim 780.6 \mathrm{eV}$ and $2 \mathrm{p}_{1 / 2}$ at $\sim 795.7 \mathrm{eV}$ ) with the spin-orbit splitting of $\sim 15.1 \mathrm{eV}$, in accordance with the data reported in the literatures [29, 30]. Two distinguishable satellite peaks centered at 789.7 and $804.7 \mathrm{eV}$ were detected at $\sim 9.0 \mathrm{eV}$ above the Co $2 \mathrm{p}_{3 / 2}$ and $2 \mathrm{p}_{1 / 2}$ main lines, which are the fingerprint for recognition of $\mathrm{Co}^{3+}$ species [31, 32]. The deconvolved O 1s spectrum in Figure 6(d) displays two photoelectron peaks at 530.0, and $531.9 \mathrm{eV}$ that can be assigned to the oxygen species of the $\mathrm{Co}-\mathrm{O}$ and $\mathrm{Zn}-\mathrm{O}$ bonds in $\mathrm{ZnCo}_{2} \mathrm{O}_{4}$ [33]. 


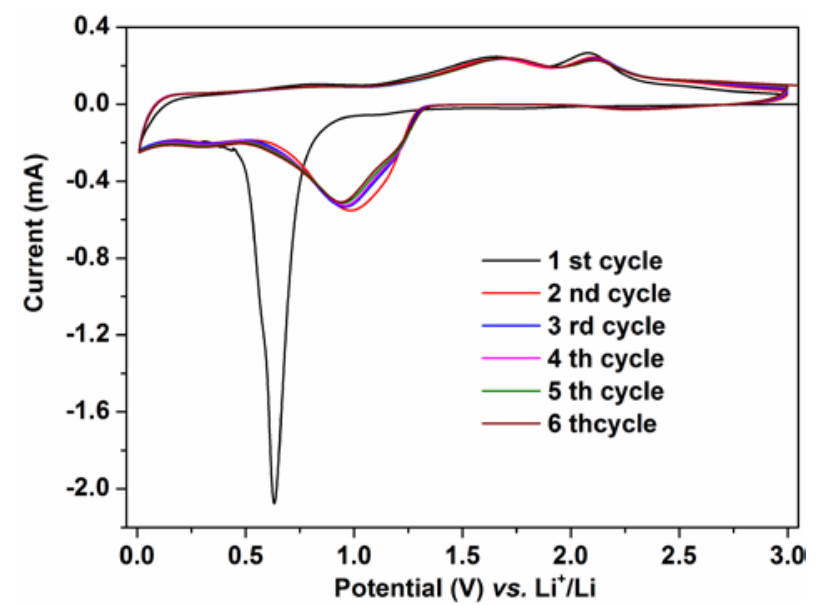

Figure 7. Cyclic voltammograms of $\mathrm{ZnCo}_{2} \mathrm{O}_{4}$ yolk-shelled microsphere electrodes at a scan rates of $0.1 \mathrm{mV} \cdot \mathrm{s}^{-1}$.

The electrochemical properties of the yolk-shelled $\mathrm{ZnCo}_{2} \mathrm{O}_{4}$ microspheres were first evaluated by cyclic voltammetry. Figure 7 demonstrates the first six consecutive cyclic voltammograms (CVs) of the electrode made by the yolk-shelled $\mathrm{ZnCo}_{2} \mathrm{O}_{4}$ microspheres. The cathodic peak at 0.63 $\mathrm{V}$ in the first cycle can be assigned to the reduction reaction of $\mathrm{ZnCo}_{2} \mathrm{O}_{4}$ with $\mathrm{Li}$ into $\mathrm{Zn}^{0}$ and $\mathrm{Co}^{0}$; the weak and broad peak between 0.2 and $0.5 \mathrm{~V}$ may be due to the further lithiation of $\mathrm{Zn}^{0}$ to give a Li-Zn alloy [5]. In the following anodic polarization, two peaks located at $1.67 \mathrm{~V}$ and $2.07 \mathrm{~V}$ in the first cycle are attributed to the oxidation of $\mathrm{Zn}^{0}$ and $\mathrm{Co}^{0}$ [34]. During the subsequent cycles, the cathodic peak shifts to $0.96 \mathrm{~V}$, which reflects the irreversible electrochemical reaction during the first discharge cycle [5]. From the second cycle onwards, the CV curves are mostly overlapped, which indicates the good reversibility of the electrochemical reactions. Based on above analysis, the lithium insertion and extraction reactions for our yolk-shelled $\mathrm{ZnCo}_{2} \mathrm{O}_{4}$ microsphere electrode are believed to proceed as follows:

$$
\begin{aligned}
& \mathrm{ZnCo}_{2} \mathrm{O}_{4}+8 \mathrm{Li}^{+}+8 \mathrm{e}^{-} \rightarrow \mathrm{Zn}+2 \mathrm{Co}+4 \mathrm{Li}_{2} \mathrm{O} \\
& \mathrm{Zn}+\mathrm{Li}^{+}+\mathrm{e}^{-} \leftrightarrow \mathrm{LiZn} \\
& \mathrm{Zn}+\mathrm{Li}_{2} \mathrm{O}+\mathrm{e}^{-} \leftrightarrow 2 \mathrm{Li}+\mathrm{ZnO}+2 \mathrm{e}^{-} \\
& 2 \mathrm{Co}+2 \mathrm{Li}_{2} \mathrm{O} \leftrightarrow 2 \mathrm{CoO}+4 \mathrm{Li}^{+}+4 \mathrm{e}^{-} \\
& 2 \mathrm{CoO}+2 / 3 \mathrm{Li}_{2} \mathrm{O} \leftrightarrow 2 / 3 \mathrm{Co}_{3} \mathrm{O}_{4}+4 / 3 \mathrm{Li}^{+}+4 / 3 \mathrm{e}^{-}
\end{aligned}
$$



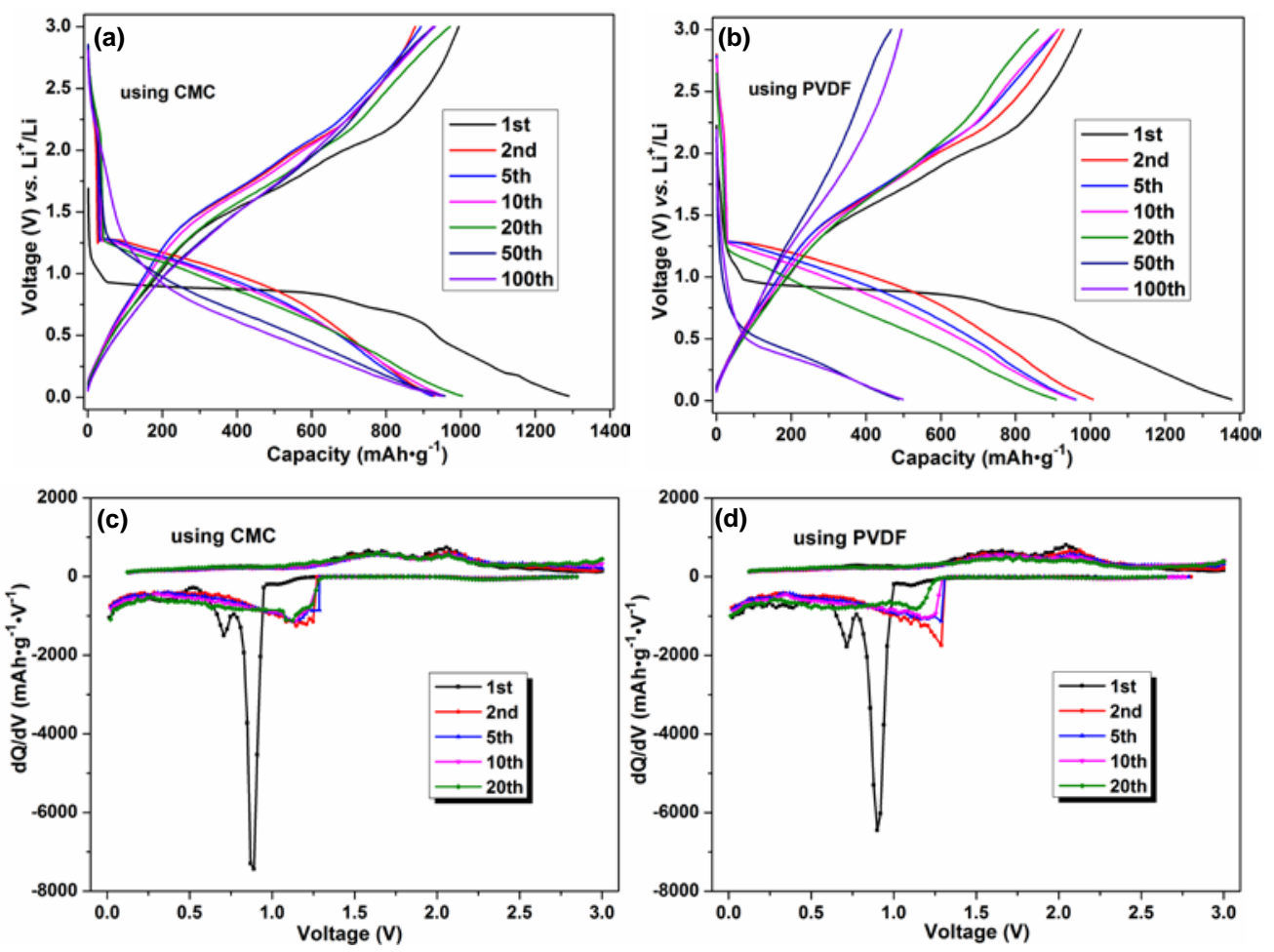

Figure 8. Typical discharge-charge curves for selected cycles and differential charge-discharge capacity versus potential of the yolk-shelled $\mathrm{ZnCo}_{2} \mathrm{O}_{4}$ microsphere electrode using CMC (a, c), and PVDF (b, d) as binder at a current density of $200 \mathrm{~mA} \cdot \mathrm{g}^{-1}$.

To investigate the difference between CMC and PVDF as the binder, the electrochemical behaviors of both the electrodes are tested under the same condition. Typical discharge-charge curves of the yolk-shelled $\mathrm{ZnCo}_{2} \mathrm{O}_{4}$ microsphere electrodes using PVDF and CMC as binders at the current density of $200 \mathrm{~mA} \cdot \mathrm{g}^{-1}$ in $\mathrm{Li}$-ion coin cells, are shown in Figure 8(a) and Figure 8(b), respectively. The initial discharge capacity of the electrodes using CMC as the binder is $1288 \mathrm{~mA}$ $\mathrm{h} \bullet \mathrm{g}^{-1}$, a bit lower than that of the electrode using PVDF as the binder $\left(1377 \mathrm{~mA} \mathrm{~h} \bullet \mathrm{g}^{-1}\right)$. Whereas, with increasing the cycling times, the discharge capacity of the one using PVDF as the binder degrades more seriously than that using CMC as the binder. It is worth pointing out that the main reasons for the existence of the initial irreversible capacity for anode materials are the irreversibility of eq (1) and the formation of a solid electrolyte interphase (SEI) layer, which forms on the surface of the anode material during the first discharge [35], and the irreversible reaction in equation (1). The differential charge and discharge profiles are shown in Figure 8 (c) and (d). Two strong cathodic peaks at 0.8 and $0.7 \mathrm{~V}$ are derived from the reaction of $\mathrm{ZnCo}_{2} \mathrm{O}_{4}$ with lithium ion to form $\mathrm{Co}, \mathrm{Zn}$ and $\mathrm{Li}_{2} \mathrm{O}$ (equation (1)), and relatively weak peaks in between 0.1 and $0.5 \mathrm{~V}$ related to the formation of LiZn alloy (equation (2)) during the first discharge process. During the charge process, one weak and broad peak located at $0.75 \mathrm{~V}$ attributed to oxidation from LiZn to $\mathrm{Zn}$. Two peaks centered at $1.6 \mathrm{~V}$ and $2.1 \mathrm{~V}$ are ascribed to the oxidations of $\mathrm{Zn}$ to $\mathrm{ZnO}$ and Co to $\mathrm{Co}_{3} \mathrm{O}_{4}$, respectively. In general, the $\mathrm{dQ} / \mathrm{dV}$ curves are consistent with the above $\mathrm{CV}$ results, but show more detailed information. Obviously, two of them show the similar shape for the peaks, 
while the peaks for the electrode using CMC as the binder overlap better than that using PVDF as the binder.
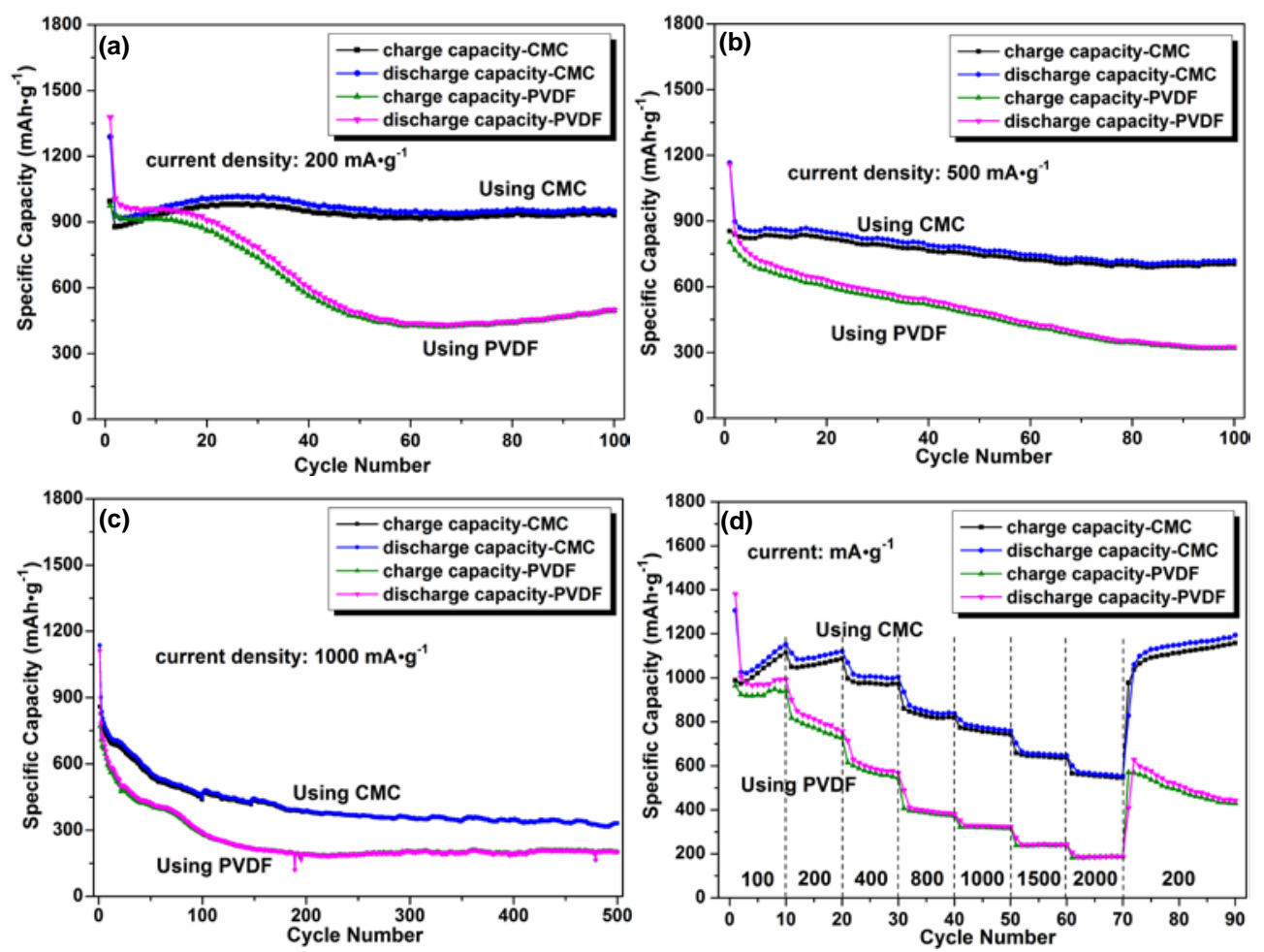

Figure 9. Cycle performances at the current density of (a) $200 \mathrm{~mA} \cdot \mathrm{g}^{-1}$, (b) $500 \mathrm{~mA} \cdot \mathrm{g}^{-1}$, (c) 1000 $\mathrm{mA} \cdot \mathrm{g}^{-1}$, and rate performances (d) for the $\mathrm{ZnCo}_{2} \mathrm{O}_{4}$ yolk-shell microsphere electrodes using CMC or PVDF as the binder, respectively.

Figure 9 shows the cycle performances of the $\mathrm{ZnCo}_{2} \mathrm{O}_{4}$ electrode using CMC or PVDF as the binder at the different current densities of 200,500 and $1000 \mathrm{~mA} \cdot \mathrm{g}^{-1}$ between 0.01 and $3.0 \mathrm{~V}$, respectively. It can be seen in Figure 9 (a) that the charge-discharge capacities of the sample using CMC as the binder increased slightly before 30 cycles because of the activated process, then kept a stable trend. After 100 cycles, this discharge capacity can be retained at $949 \mathrm{~mA} \mathrm{~h} \cdot \mathrm{g}^{-1}$. The capacity of the electrode using PVDF as the binder degrade drastically in the initial 60 cycles, then stabilized at $498 \mathrm{~mA} \mathrm{~h} \cdot \mathrm{g}^{-1}$ after 100 cycles. When the current density increased to $500 \mathrm{~mA} \cdot \mathrm{g}^{-1}$ as shown in Figure 9 (b), the electrode using CMC as the binder still retain the discharge capacity of $718 \mathrm{~mA} \mathrm{~h} \bullet \mathrm{g}^{-1}$ for the 100th cycle, versus $325 \mathrm{~mA} \mathrm{~h} \cdot \mathrm{g}^{-1}$ for that one using PVDF as the binder.

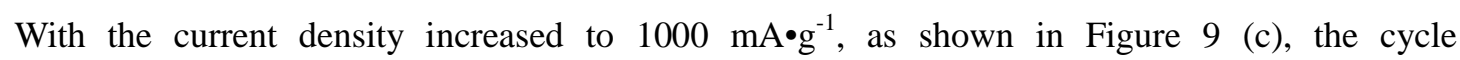
performance of the sample using CMC as the binder are also better than that using PVDF as the binder. The electrode using CMC as the binder nicely yields a discharge capacity of $331 \mathrm{~mA} \mathrm{h \bullet \textrm {g } ^ { - 1 }}$ after 500 cycles, while that using PVDF as the binder just remained at $202 \mathrm{mAh} / \mathrm{g}$ by the 500th cycle. Figure 9 (d) compares the rate capabilities of the $\mathrm{ZnCo}_{2} \mathrm{O}_{4}$ yolk-shelled microsphere electrodes using CMC and PVDF as binders at different current densities. The discharge capacity of the sample using PVDF as the binder decreases significantly form 100 to $2000 \mathrm{~mA} \cdot \mathrm{g}^{-1}$, whereas that using CMC as binder decreases much more slowly at the same current density. The current 
density was increased stepwise from 100 to 200, 400, 800, 1000, 1500 and $2000 \mathrm{~mA} \cdot \mathrm{g}^{-1}$; where stable capacities of $1151,1120,1003,838,759,647$, and $553 \mathrm{~mA} \mathrm{~h} \cdot \mathrm{g}^{-1}$ for the electrode using CMC as the binder are obtained, respectively. All are higher than that using PVDF as the binder,

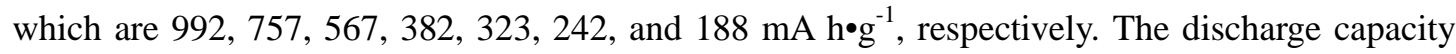
for the one using CMC as the binder can recover $1193 \mathrm{~mA} \mathrm{~h} \cdot \mathrm{g}^{-1}$ when the current density reduced to $200 \mathrm{~mA} / \mathrm{g}$, while only $442 \mathrm{~mA} \mathrm{~h} \cdot \mathrm{g}^{-1}$ for that using PVDF as the binder. Obviously, the electrochemical behaviors are improved to a large extent by changing the binder, especially for the rate capability, which is a very important property for electrode materials. The above results demonstrate that the binder plays an important role in the cycle stability of electrode [36-39].

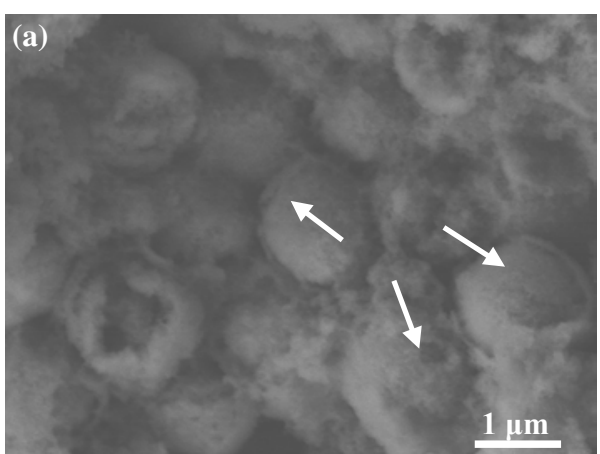

(c)

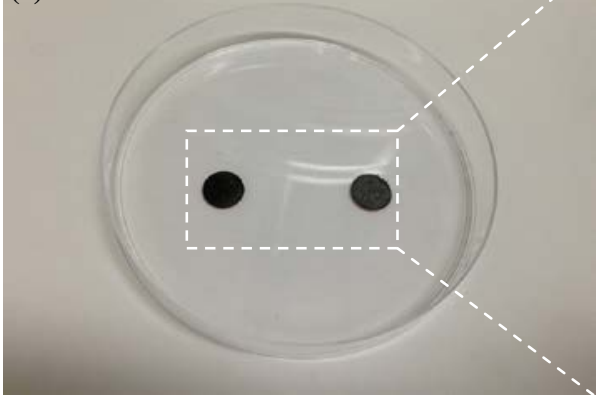

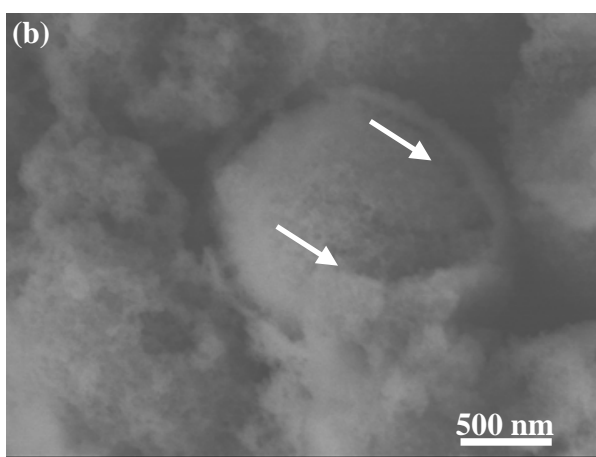

(d)

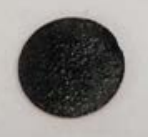

using CMC

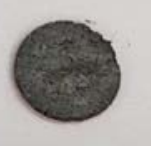

using PVDF

Figure 10. (a, b) Low and high magnification FESEM images of the electrode made of $\mathrm{ZnCo}_{2} \mathrm{O}_{4}$ yolk-shelled like microspheres after 100 cycles testing at $500 \mathrm{~mA} \cdot \mathrm{g}^{-1}$. (c, d) Low and high magnification optical digital photos of the electrodes made from yolk-shelled $\mathrm{ZnCo}_{2} \mathrm{O}_{4}$ microspheres using CMC or PVDF as the binder after cycling 100 times at the current density of $500 \mathrm{~mA} \cdot \mathrm{g}^{-1}$.

The superior and excellent electrochemical behavior of the $\mathrm{ZnCo}_{2} \mathrm{O}_{4}$ yolk-shelled microspheres could be attributed to the following factor. Firstly, the unique structures of the $\mathrm{ZnCo}_{2} \mathrm{O}_{4}$ sample possesses the pores on the surface and the empty spaces between the core and the shell; the former ones provide a short pathway for $\mathrm{Li}^{+}$diffusion and a large electrode-electrolyte contract area for high $\mathrm{Li}^{+}$migration across the interface, while the latter ones could significantly improve the structure integrity by partly mitigating the mechanical strain induced by volume change associated with the repeated $\mathrm{Li}^{+}$insertion/extraction process during cycling, this is proven by the FESEM images shown in Figure 10(a) and Figure 10(b), where the total morphology of the sample after 100 charge-discharge cycles was still similar to that of the freshly prepared sample. Secondly and 
importantly, CMC as the binder can stick to the collector more stable than PVDF. As illustrated in Figure 10 (c) and (d), which shows the optical digital photos of the electrodes made from yolk-shelled $\mathrm{ZnCo}_{2} \mathrm{O}_{4}$ microspheres using CMC or PVDF as the binder after cycling 100 times. It can be clearly observed that the electrode using CMC as the binder is smoother and tighter than that using PVDF as the binder.

\section{Conclusion}

In summary, yolk-shelled $\mathrm{ZnCo}_{2} \mathrm{O}_{4}$ microspheres are generated via annealing ZnCo-glycolate solid microspheres, which were synthesized by a simple route without adding any surfactant, template or precipitant. The as-synthesized yolk-shelled $\mathrm{ZnCo}_{2} \mathrm{O}_{4}$ microspheres have been applied as the anode of Li-ion batteries, which show superior capacity and cycling performance. Interestingly, by adopting CMC as the green binder, the electrochemical performance for the yolk-shelled $\mathrm{ZnCo}_{2} \mathrm{O}_{4}$ microspheres are greatly enhanced, including cyclability, rate capability. The present strategy could provide a feasible and effective means of achieving improved cycling performance and rate capability of high-capacity battery electrode materials that are subject to large volume changes.

Acknowledgements. This work was supported by the National Basic Research Program of China (973 Project of China, No. 2011CB935901), the National Natural Science Fund of China (No. 91022033) and the Australian Research Council (ARC) through a Discovery Project (DP110103909). Many thanks also go to Dr. T. Silver for critical reading of the manuscript.

\section{References}

[1] P. Lavala, J. L. Tirado, T. Vidal-Abarca, Electrochim. Acta 2007, 52, 7986.

[2] J. F. Li, S. L. Xiong, Y. R. Liu, Z. C. Ju, Y. T. Qian, ACS Appl. Mater. Interfaces 2013, 5, 981-988.

[3] F. M. Courtel, H. Duncan, Y. Abu-Lebdeh, I. J. Davidson, J. Mater. Chem. 2011, 21, 10206

[4] S. W. Kim, H. W. Lee, P. Muralidharan, D. H. Seo, W. S. Yoon, D. K. Kim, K. Kang, Nano Res. 2011, 4, $505-510$

[5] Y. Sharma , N. Sharma, G. V. S. Rao, B. V. R. Chowdari, Adv. Funct. Mater. 2007, 17, 2855-2861.

[6] Y. Sharma , N. Sharma, G. V. S. Rao, B. V. R. Chowdari, Electrochim. Acta 2008, 53, 2380-2385.

[7] T. Y. Wei, C. H. Chen, H. C. Chien, S. Y. Lu, C. C. Hu, Adv. Mater. 2010, 22, 347.

[8] Z. Y. Wang, L. Zhou, X. W. Lou, Adv. Mater. 2012, 24, 1903.

[9] X. W. Lou, L. A. Archer, Z. C. Yang, Adv. Mater. 2008, 20, 3987-4019.

[10] Q. Zhang, W. S. Wang, J. Goebl, Y. D. Yin, Nano Today 2009, 4, 494-507. 
[11] J. Hu, M. Chen, X. Fang, L. Wu, Chem. Soc. Rev. 2011, 40, 5472-5491.

[12] J. F. Li, S. L. Xiong, Y. R. Liu, Z. C. Ju, Y. T. Qian, Nano Energy 2013, doi: 10.1016/j.nanoen.2013.06.003.

[13] L. L. Hu, B. H. Qu, C. C. Li, Y. J. Chen, L. Mei, D. N. Lei, L. B. Chen, Q. H. Li, T. H. Wang, J. Mater. Chem. A 2013, 1, 5596-5602.

[14] Q. S. Xie, F. Li, H. Z. Guo, L. S. Wang, Y. Z. Chen, G. H. Yue, D. L. Peng, ACS Appl. Mater. Interfaces 2013, 5, 5508-5517.

[15] S. H. Choi, K. C. Kang, ChemSusChem 2013, doi: 10.1002/cssc.201300300.

[16] J. Chong, S. Xun, H. Zheng, X. Song, G. Liu, P. Ridgway, J. Q. Wang, V. S. Battaglia, J. Power Sources 2011, 196, 7707-7714.

[17] D. Munao, J. W. M. Van-Erven, M. Valvo, E. Garcia-Tamayo, E.M. Kelder, J. Power Sources 2011, 196, 6695-6702.

[18] S. L. Chou, J. Z. Wang, C. Zhong, M. M. Rahman, H. K. Liu, S. X. Dou, Electrochim. Acta 2009, 54, 7519-7524.

[19] J. Li, H. M. Dahn, L. J. Krause, D. B. Le, J. R. Dahn, J. Electrochem. Soc. 2008, 155, A812-A816.

[20] S. L. Chou, J. Z. Wang, H. K. Liu, S. X. Dou, J. Phys. Chem. C 2011, 115, 16220-16227.

[21] J. T. Lee, Y. J. Chua, X. W. Peng, F. M. Wang, C. R. Yang, C. C. Li, J. Power Sources 2007, 173, 985-989.

[22] W. Porcher, B. Lestriez, S. Jouanneau, D. Guyomard, J. Power Sources 2010, 195, 2835-2843.

[23] J. T. Xu, S. L. Chou, Q. F. Gu, H. K. Liu, S. X. Dou, Journal of Power Sources 2013, 225, 172-178.

[24] G. T. Kim, S. S. Jeong, M. Joost, E. Rocca, M. Winter, S. Passerini, A. Balducci, J. Power Sources 2011, 196, 2187-2194.

[25] M. He, L. X. Yuan, W. X. Zhang, X. L. Hu, Y. H. Huang, J. Phys. Chem. C 2011, 115, 15703-15709.

[26] Y. L. Wang, X. C. Jiang, Y. N. Xia, J. Am. Chem. Soc. 2003, 125, 16176-16177.

[27] J. G. Guan, F. Z. Mou, Z. G. Sun, W. D. Shi, Chem. Commun. 2010, 46, 6605-6607.

[28] S. Vijayanand, P. A. Joy, H. S. Potdar, D. Patil, P. Patil, Sens. Actuators B: Chemical 2011, 152, 121-129.

[29] J. F. Marco, J. R. Gancedo, M. Gracia, J. L. Gautier, E. I. Ríos, H. M. Palmer, C. Greaves, F. J. Berry, J. Mater. Chem. 2001, 11, 3087.

[30] A. L. Rosa-Toro, R. Berenguer, C. Quijada, F. Montilla, E. Morallón, J. L. Vázquez, J. Phys. Chem. B 2006, $110,24021$.

[31] W. Wei, W. Chen, D. G. Ivey, Chem. Mater. 2008, 20, 1941.

[32] J. F. Li, S. L.Xiong, X. W.Li, Y. T.Qian, Nanoscale 2013, 5, 2045-2054.

[33] W. Luo, X. L. Hu, Y. M. Sun , Y. H. Huang, J. Mater. Chem. 2012, 22, 8916-8921. 
[34] H. Li, X. Huang, L. Chen, Solid State Ionics 1999, 123, 189-197.

[35] D. Bar-Tow, E. Peled, L. Burstein, J. Electrochem. Soc. 1999, 146, 824.

[36] H. Buqa, M. Holzapfel, F. Krumeich, C. Veit, P. Novak, J. Power Sources 2006, 161, 617.

[37] B. Lestriez, S. Bahri, I. Sandu, L. Roué, D. Guyomard, Electrochem. Commun. 2007, 9, 2801.

[38] N. S. Hochgatterer, M. R. Schweiger, S. Koller, P. R. Raimann, T. Wöhrle, C. Wurm, M. Winter, Electrochem. Solid-State Lett. 2008, 11, A76.

[39] J. Li, R. B. Lewis, J. R. Dahn, Electrochem. Solid-State Lett. 2007, 10, A17. 